\title{
Editorial
}

Dermatology

\section{A 30-Year-Long Journey as the Fifth Editor of This Journal (1986-2015)}

\author{
Jean-Hilaire Saurat \\ SCAHT - Dermatotoxicologie, Centre Médical Universitaire, Geneva, Switzerland
}

In June 1985, Thomas Karger visited me in Geneva where I had been Head of the Dermatology Department at the University Hospital since November 1981.

Prof. Rudolph Schuppli, a distinguished gentleman with unique elegance and culture, who had been Chief Editor of Dermatologica since 1959, had just decided to step down after 27 years.

Thomas Karger offered me the position. I was 42 years old and loved medical editing. I accepted at once. I am now 72 years old, and it is time to follow Prof. Rudolph Schuppli on the short list of past Chief Editors since the journal's inception in 1893. It is indeed a short list, with only five people on it in 123 years, that is, a mean period of 24.6 years in the position. Such continuity is rare and it reflects the philosophy of this publishing house which is run by a family rather than by a company.

During my term, I met, at least once a year, with Thomas Karger himself, and got full freedom for the running of the journal. In 1992, I was amazed when he at once accepted my proposal to change its name to Dermatology. He last visited me in Geneva in April 2013, and we agreed upon December 2015 as the term of my editorship, because I would then have completed 30 years at this task. A round number that does not, however, surpass the term of Erich Hoffmann, from 1908 to 1938, a whole 31 years!

\section{KARGER 125\%}

(c) 2015 S. Karger AG, Basel

$1018-8665 / 15 / 2314-0291 \$ 39.50 / 0$

E-Mail karger@karger.com

www.karger.com/drm
Historically, this journal had been the organ of the Swiss Society of Dermatology, which had provided significant financial support. When the Society's main focus moved from academic to professional issues, this support was cancelled. Due to the worldwide distribution of Dermatology, the journal does not attract industry inserts from Switzerland; I therefore launched a Swiss bulletin, 'Dermatologica Helvetica', the revenues of which support a link between Dermatology and the Swiss Society of Dermatology.

During my term as president of the International League of Dermatological Societies (ILDS), and since Switzerland is a neutral country, Thomas Karger consented to Dermatology publishing the first-ever ILDS Newsletter, 4 pages in each issue, at no cost to the ILDS.

Over this 30-year journey, innumerable colleagues worldwide have supported Dermatology, acting on the Editorial Board and as reviewers. It is so refreshing to see how the medical academic world still stands up, and how its members still devote their precious time.

I am confident that the new Editorial Board under the leadership of Gregor Jemec, who has already trained with the Karger online-only/open-access Case Reports in Dermatology, will rise successfully to the challenge.

He may have 30 years in which to do so!

Prof. Jean-Hilaire Saura

SCAHT - Dermatotoxicologie, Centre Médical Universitaire

1 rue Michel-Servet

$\mathrm{CH}-1211$ Genève (Switzerland)

E-Mail Jean.Saurat@ unige.ch 


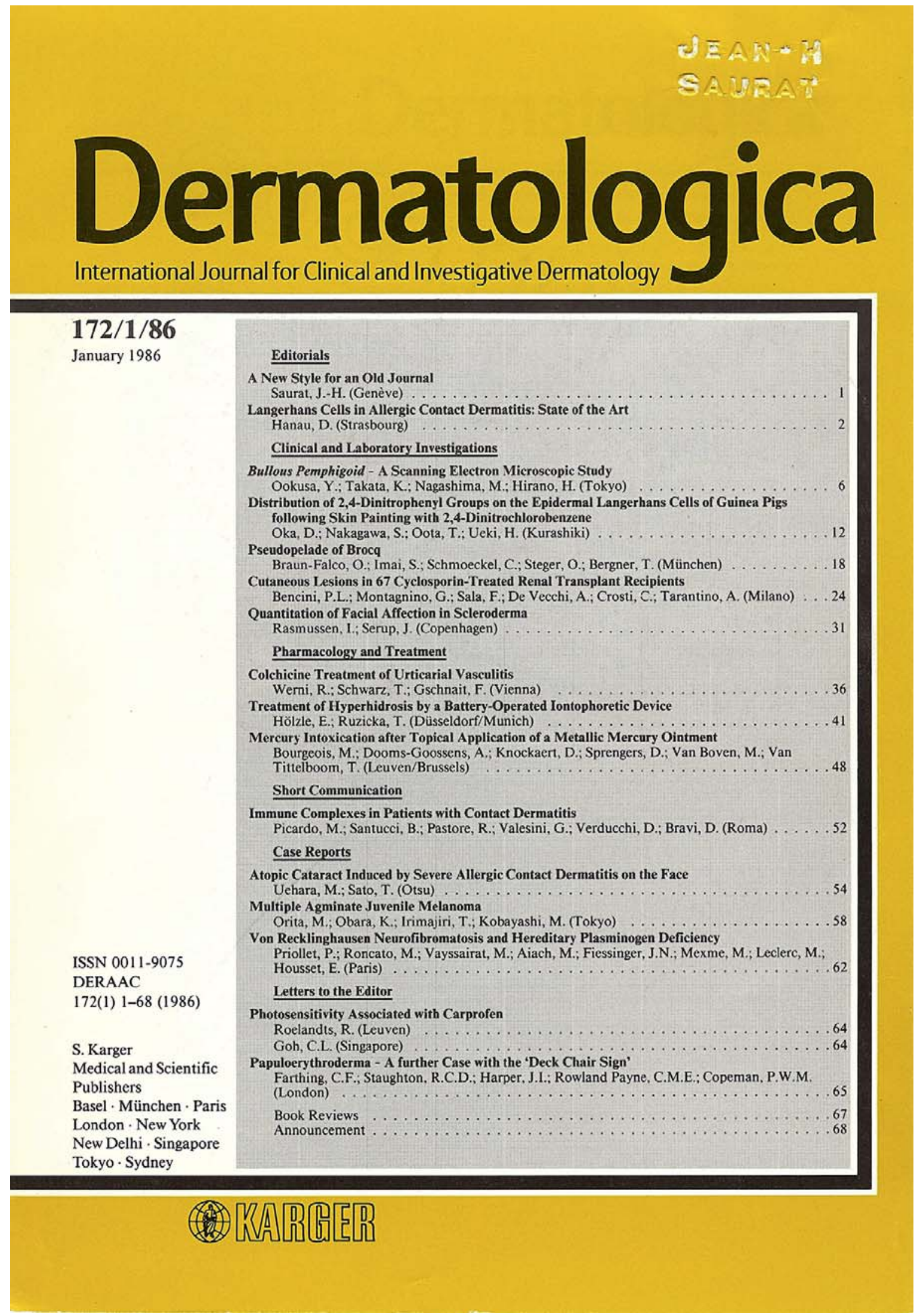

